\title{
Motor Axonal Regeneration after Partial and Complete Spinal Cord Transection
}

\author{
Paul Lu, ${ }^{1,2}$ Armin Blesch, ${ }^{1,3}$ Lori Graham, ${ }^{1}$ Yaozhi Wang, ${ }^{1}$ Ramsey Samara, ${ }^{1}$ Karla Banos, ${ }^{1}$ Verena Haringer, ${ }^{1}$ \\ Leif Havton, ${ }^{4}$ Nina Weishaupt, ${ }^{5}$ David Bennett, ${ }^{5}$ Karim Fouad, ${ }^{5}$ and Mark H. Tuszynski ${ }^{1,2}$ \\ ${ }^{1}$ Department of Neurosciences, University of California, San Diego, La Jolla, California 92093, ${ }^{2}$ Veterans Administration Medical Center, San Diego, \\ California 92161, ${ }^{3}$ Spinal Cord Injury Center, Heidelberg University Hospital, D-69120 Heidelberg, Germany, ${ }^{4}$ Department of Anesthesiology, University of \\ California, Irvine, Irvine, California 92697, and ${ }^{5}$ University of Alberta, Centre for Neuroscience, Edmonton, Alberta T6G 2E1, Canada
}

We subjected rats to either partial midcervical or complete upper thoracic spinal cord transections and examined whether combinatorial treatments support motor axonal regeneration into and beyond the lesion. Subjects received cAMP injections into brainstem reticular motor neurons to stimulate their endogenous growth state, bone marrow stromal cell grafts in lesion sites to provide permissive matrices for axonal growth, and brain-derived neurotrophic factor gradients beyond the lesion to stimulate distal growth of motor axons. Findings were compared with several control groups. Combinatorial treatment generated motor axon regeneration beyond both $\mathrm{C} 5 \mathrm{hemisection}$ and T3 complete transection sites. Yet despite formation of synapses with neurons below the lesion, motor outcomes worsened after partial cervical lesions and spasticity worsened after complete transection. These findings highlight the complexity of spinal cord repair and the need for additional control and shaping of axonal regeneration.

\section{Introduction}

Numerous mechanisms limit axonal regeneration in the adult CNS, including factors both in the lesioned environment and intrinsic to the injured neuron. Environmental mechanisms limiting axonal regeneration include a lack of formation of growth-permissive matrices in the lesion site, an absence of growth factor production in appropriate temporal and spatial gradients to stimulate growth, and the presence of numerous inhibitory molecules associated with myelin and the extracellular matrix (He and Koprivica, 2004; Buchli and Schwab, 2005; Fawcett, 2006; Fitch and Silver, 2008). In addition, the centrally injured adult neuron fails to upregulate intrinsic sets of regeneration-associated genes to initiate and sustain regeneration (Filbin, 2006; Kadoya et al., 2009; Sun et al., 2011).

Recently, we and others have reported regeneration of central axons using experimental strategies that target several of these neural mechanisms simultaneously (Lu et al., 2004; Pearse et al., 2004; Houle et al., 2006; Alto et al., 2009; Kadoya et al., 2009; Alilain et al., 2011; Bonner et al., 2011). For example, the provision of a supportive matrix in a spinal cord injury (SCI) site, a growth factor gradient within and beyond the injury, and activation of intrinsic neuronal growth programs by cAMP injections or peripheral nerve conditioning lesions, support sensory axonal

Received Jan. 20, 2012; revised April 8, 2012; accepted April 11, 2012

Author contributions: P.L., A.B., K.F., and M.H.T. designed research; P.L., A.B., L.G., Y.W., R.S., K.B., V.H., N.W., D.B., and K.F. performed research; P.L., A.B., L.G., Y.W., R.S., K.B., V.H., L.H., N.W., D.B., K.F., and M.H.T. analyzed data; P.L., A.B., and M.H.T. wrote the paper.

This work was supported by grants from the Veterans Administration, the National Institutes of Health (NIH Grant NS049881), Craig H. Neilsen Foundation, Canadian Spinal Research Organization, and Bernard and Anne Spitzer. We thank Leo Sanelli and Romana Vavrek for technical assistance.

Correspondence should be addressed to Dr. Mark H. Tuszynski, Department of Neurosciences, 0626, University of California, San Diego, 9500 Gilman Drive, La Jolla, CA 92093-0626. E-mail: mtuszynski@ucsd.edu.

DOI:10.1523/JNEUROSCI.0308-12.2012

Copyright $\odot 2012$ the authors $\quad 0270-6474 / 12 / 328208-11 \$ 15.00 / 0$ regeneration beyond SCI sites ( $\mathrm{Lu}$ et al., 2004). Indeed, these approaches are successful when administered 1 year after the original injury (Kadoya et al., 2009). Moreover, growth factors can be used in combination with other strategies to guide regenerating sensory axons into correct targets beyond the lesion site (Alto et al., 2009).

Despite these recent successes in models of partial SCI, axonal regeneration and functional recovery after complete spinal cord transection remain an unattained goal of the field. This is particularly important because the majority of human injuries are severe in extent ("ASIA A"), resulting in complete and permanent loss of function below the lesion (Fawcett et al., 2007). Following complete spinal cord transection, spared axons are not available to contribute to the plasticity and recovery of function that can occur after partial injuries (Bareyre et al., 2004; Courtine et al., 2008; Rosenzweig et al., 2010). While previous studies have reported regeneration and functional recovery after complete thoracic transection (Cheng et al., 1996; Ramón-Cueto et al., 2000), efforts at replication have not succeeded (Levi et al., 2002; Steward et al., 2006). A recent study reported that postnatal deletion of the tumor suppressor gene, PTEN (phosphatase tensin homolog), resulted in corticospinal axonal regeneration after "complete crush" of the spinal cord (Liu et al., 2010), but this lesion could spare small bridges of host tissue.

Given the recent success of combinatorial strategies in achieving sensory and respiratory motor axonal regeneration after partial SCI (Alilain et al., 2011), and the need to examine therapies in the most clinically relevant models, we tested the hypothesis that combinatorial therapies would promote motor axonal regeneration in the extraordinarily challenging model of complete spinal cord transection. We now report brainstem motor axonal regeneration and synapse formation after both T3 complete and C5 
partial spinal cord transection. Yet despite motor axon regeneration beyond the lesion site, functional outcomes actually worsen, highlighting the need for additional control and shaping of the regenerative response.

\section{Materials and Methods Methods summary}

The ability of combinatorial treatment strategies to influence motor axonal growth and regeneration was examined in two models of spinal cord injury in Fischer 344 rats: $C 5$ lateral hemisection $(N=60$ rats $)$ in which the complete lateral half of the spinal cord was transected, and complete T3 transection ( $N=14$ rats). The $\mathrm{C} 5$ hemisection model was first used to establish which elements of a combinatorial therapy were required to support brainstem motor axon bridging, and accordingly incorporated extensive control groups; the optimal approach from this model was then tested in the model of complete T3 spinal cord transection (see Fig. 1). In all cases, subjects survived 3 months after injury.

Five groups of animals were studied in the C5 hemisection model. In Group 1, Full combination treatment subjects received a syngenic bone marrow stromal cell (MSC) graft in the lesion site, gradients of BDNF within and beyond the lesion site, and cAMP injections into the brainstem $(N=12)$. BDNF was administered in the graft using genetically engineering MSCs (Lu et al., 2005); BDNF was administered caudal to the lesion site using injections of viral vectors expressing BDNF, 1.5 and $2.5 \mathrm{~mm}$ caudal to the lesion site (see below, Detailed methods). cAMP was administered directly into the reticular motor nucleus of the pons (pontine gigantocellular reticular nucleus) using a pulled glass micropipette, injecting $0.5 \mu \mathrm{l}$ of a $25 \mathrm{~mm}$ solution over $5 \mathrm{~min}$ (Jin et al., 2002). In Group 2, BDNF treatment subjects received BDNF-expressing MSC grafts in the lesion site and BDNF viral vector injections caudal to the lesion. Vehicle rather than cAMP was injected into the pontine reticular nucleus $(N=12)$. In Group 3, cAMP treatment subjects received cAMP injections into the pontine reticular nucleus, BDNF-expressing cell grafts in the lesion site, but no BDNF-expressing viral vectors beyond the lesion $(N=12)$. In Group 4, lesioned controls received a lesion only and no other interventions $(N=12)$. In Group 5 , full treatment without graft subjects received cAMP injections into the pontine reticular nucleus, and injections of viral vectors expressing BDNF 1.5 and $2.5 \mathrm{~mm}$ caudal to the lesion site, but did not receive cells into the lesion site $(N=12)$. This group controlled for the possibility that cAMP and/or BDNF expression would promote sprouting or synaptic rearrangements of spared host axons sprouting across the spinal cord midline to influence outcomes.

As will be shown below, results of $\mathrm{C} 5$ hemisection studies indicated that full combination treatment achieved significantly greater motor axonal bridging beyond the lesion site compared with any other group. Accordingly, in the severe model of T3 complete transection, one group received full combination treatment $(N=8)$, as described above. A second, lesioned control group received lesions and no other intervention $(N=6)$.

\section{Detailed methods}

\section{Cell culture}

Primary MSCs were isolated from adult Fischer 344 female rats according to the method of Azizi et al. (1998) and cultured as described previously (Lu et al., 2005). The cells were then transduced with retroviral vectors expressing either brain-derived neurotrophic factor (BDNF) or jellyfish green fluorescent protein (GFP) reporter gene at passage 1 or 2 as described previously (Lu et al., 2005). Two-site ELISA measured quantities of BDNF secreted by BDNF-transduced MSCs: these cells secreted $45.7 \pm$ 3 ng of BDNF per $10^{6}$ cells per day into the conditioned medium, whereas GFP-transduced or naive cells produced undetectable amounts of BDNF. BDNF- or GFP-expressing MSCs were harvested and implanted in vivo as described below.

\section{Production of lentiviral and adenoassociated viral vectors}

Lentiviral vectors expressing either enhanced GFP or human BDNF were produced according to the method of Taylor et al. (2006). Briefly, the chicken $\beta$-actin promoter/CMV enhancer (CAG) hybrid was used to express BDNF and GFP. Titers of GFP-expressing virus were determined by infection of HEK293T cells using serial dilutions. Vector stocks were assayed for p24 antigen levels using an HIV-1 p24-specific ELISA kit (DuPont). Virus preparations containing $150-200 \mu \mathrm{g} / \mathrm{ml} \mathrm{p} 24$ and $1-5 \times$ $10^{8} \mathrm{IU} / \mathrm{ml}$ were used. Adenoassociated viral 2 (AAV2) vectors carrying either GFP or BDNF genes were purchased from the Gene Therapy Center, University of North Carolina at Chapel Hill (Chapel Hill, NC). AAV2 vectors were generated using a triple transfection protocol and purified using a sequential process of nuclei isolation, density gradient centrifugation. Vectors were titered by dot-blot and diluted to $10^{12}$ vector genomes $(\mathrm{vg}) / \mathrm{ml}$ for in vivo use.

\section{Surgery}

A total of 85 adult female Fischer 344 rats (150-200 g) were subjects of this study. NIH guidelines for laboratory animal care and safety were followed. Animals were randomly divided into groups described above. An average of six animals underwent lesions and treatment per day, typically drawn from three different groups to randomize the order in which groups entered the study. All animals were enrolled and surgeries were performed in the $\mathrm{C} 5$ hemisection experiments over a 5 week period $(N=60$ animals). Animal enrollment and lesions for the T3 transection experiments were performed over a $5 \mathrm{~d}$ period $(N=14$ animals $)$. Surgeons were blinded to the identity of the type of vector injected below the lesion (BDNF vs GFP), and the substance injected into the brainstem (cAMP vs vehicle). To make lateral C5 hemisection lesions, the right hemicord was removed using iridectomy scissors and microaspiration, with visual verification to ensure complete transection ventrally and laterally. Five microliters of BDNF-expressing MSCs, 75,000 cells/ $\mu$ l, were injected through a glass micropipette into the lateral hemisection site after completing the lesion. T3 complete transections were made similarly, except that the T3 spinal cord was transected bilaterally. Seven microliters of BDNF-expressing MSCs were transplanted into the lesion site. For cAMP injections, $2 \mu \mathrm{l}$ of $25 \mathrm{~mm}$ dibutyryl-cAMP were injected into either the right ( $\mathrm{C} 5$ hemisection) or right and left (T3 complete transection) gigantocellular pontine reticular nuclei using a glass micropipette in four sites per side as follows: site 1: AP, $-11 \mathrm{~mm}$; lateral, 0.8 $\mathrm{mm}$; depth, $7.3 \mathrm{~mm}$; site 2: AP, $-12.5 \mathrm{~mm}$; lateral, $0.8 \mathrm{~mm}$; depth, 7.3 $\mathrm{mm}$; site 3: AP, $-11 \mathrm{~mm}$; lateral, $0.8 \mathrm{~mm}$; depth, $8.2 \mathrm{~mm}$; site 4: AP, $-12.5 \mathrm{~mm}$; lateral, $0.8 \mathrm{~mm}$; depth, $8.2 \mathrm{~mm}$ (Jin et al., 2002). Injections were placed $5 \mathrm{~d}$ before spinal cord lesions, to amplify intrinsic neuronal growth state (Neumann et al., 2002; Qiu et al., 2002). Control subjects received injections of PBS using the same techniques. For in vivo growth factor gene delivery, viral vectors expressing BDNF were injected 1.5 and $2.5 \mathrm{~mm}$ caudal to the lesion site, targeting ventral gray matter (see Fig. $1 A$ ). In previous studies, we found that lentiviral vectors nearly exclusively infect glia in the spinal cord (Taylor et al., 2006; Kadoya et al., 2009), and AAV2 vectors exclusively infect neurons (see Fig. $1 F, G$ ), consistent with previous reports (Peel et al., 1997). A combination of lentiviral injection $1.5 \mathrm{~mm}$ caudal to the lesion site and AAV2 vector $2.5 \mathrm{~mm}$ caudal to the lesion site maximizes the distance over which motor axons regenerated compared with exclusive AAV2 vector injections; accordingly, we injected lenti-BDNF $1.5 \mathrm{~mm}$ and AAV2-BDNF $2.5 \mathrm{~mm}$ caudal to the lesion site. Two microliters of virus solution were injected into each site targeting host ventral gray matter (coordinates, $0.7 \mathrm{~mm}$ lateral to midline; depth, 1.5 and $2 \mathrm{~mm}$ ) using a pulled glass pipette connected to a PicoSpritzer delivering $20 \mathrm{nl} /$ pulse. Three weeks before killing, $2 \mu \mathrm{l}$ of $10 \%$ biotin dextran amine (BDA) (10,000 MW; D1956; Invitrogen) tracer was injected into the right gigantocellular reticular nuclear $(0.5 \mu \mathrm{l}$ /site) using the coordinates of cAMP injections.

\section{Histology and immunolabeling}

Three months after lesions, animals were transcardially perfused with $4 \%$ paraformaldehyde and an $8 \mathrm{~mm}$ length of spinal cord was entirely sectioned horizontally through its dorsal-to-ventral axis on a cryostat set at $30 \mu \mathrm{m}$ thickness; the center of the block corresponded to the center of the lesion site. Every sixth section was Nissl stained and remaining sections were serially collected into 24 -well plates for immunocytochemistry. Sections were processed free-floating in nets to minimize section damage during gentle incubations and washes. For visualization of BDA-labeled 
reticulospinal motor axons at the lightmicroscopic level, every sixth section was labeled with avidin-biotinylated peroxidase complex (1:100; Elite kit; Vector Laboratories) as described previously (Lu et al., 2005). To study interactions between BDA-labeled reticulospinal axons and AAV2 or lentiviral vector transduced neurons and glia expressing BDNF, BDA labeling (Vector brown) was combined with BDNF immunolabeling [polyclonal antibody at 1:1000 from University of Chicago (Chicago, IL) with Vector blue for visualization] using VECTASTAIN multiple antigen labeling kit (Vector Laboratories). To examine association of BDA-labeled reticulospinal tract axons with host neural cells, BDA, GFP, and GFAP triple-fluorescent immunolabeling was performed, or GFP and GFAP double-fluorescent labeling were performed subsequently in the same sections following light level BDA labeling using streptavidinconjugated Alexa 594 (Invitrogen) and antibodies against GFP (1:1500; polyclonal from Invitrogen) and GFAP (1:1500; monoclonal from Millipore) incubated overnight at $4^{\circ} \mathrm{C}$. After washes, sections were incubated with Alexa 488 and Alexa 647 fluorophore-conjugated secondary antibodies for $2.5 \mathrm{~h}$ at room temperature (1:300; Invitrogen). To detect synapse formation by regenerating reticulospinal axons with host motor neurons, we performed triple-fluorescent immunolabeling for BDA, synaptophysin (1: 1000; monoclonal from Millipore), and vesicular glutamate transporter 1 (VGlut1) (1:5000; polyclonal from Millipore); or BDA, synaptophysin, and choline acetyltransferase (ChAT) (1:250; polyclonal from Millipore). To assess myelination of regenerating axons, labeling was performed for BDA and myelin-associated glycoprotein (MAG) (1:1000; monoclonal from Millipore) or myelin basic protein (MBP) (1:200; polyclonal from Millipore). Triple-fluorescent immunolabeling was also performed for serotonin (5-HT) (1:10,000; polyclonal from ImmunoStar), GFP, and GFAP to examine serotonergic axon regeneration and interaction with host neural cells.

\section{Axon quantification}

Reticulospinal axons that penetrated into grafts and crossed beyond the graft/lesion interface were quantified in every subject in a series of one-in-six BDA-labeled sections. Using a $10 \times$ ocular with a calibrated grid and a $20 \times$ objective $(200 \times$ total), axons crossing the dorsal-ventral axis of the spinal cord were quantified in 250,500,1000, 2000 , and $3000 \mu \mathrm{m}$ beyond the caudal graft/lesion border. The host/ lesion boundary was identified under phase contrast optics as a distinct change in cellular morphology from sheets of smaller, rounded cells within grafts to neurons and white matter bundles in host spinal cord beyond the lesion. In addition, GFAP labeling identified the graft/host interface in each animal (see Figs. $1 C, 2 A-C$ ). Myelination of BDAlabeled reticulospinal axons was quantified $3 \mathrm{~mm}$ above the lesion, within the lesion site, and $0.5 \mathrm{~mm}$ caudal to the lesion site in MAG- and MBP-labeled sections using high-resolution confocal miscroscopy. A minimum of 100 axons per subject was examined and recorded, and the frequency of myelination was expressed as the percentage of total axons examined. All quantification was performed by an observer blinded to group identity using coded slides. The code was broken upon completion of quantification. $600 \mu \mathrm{m}$.
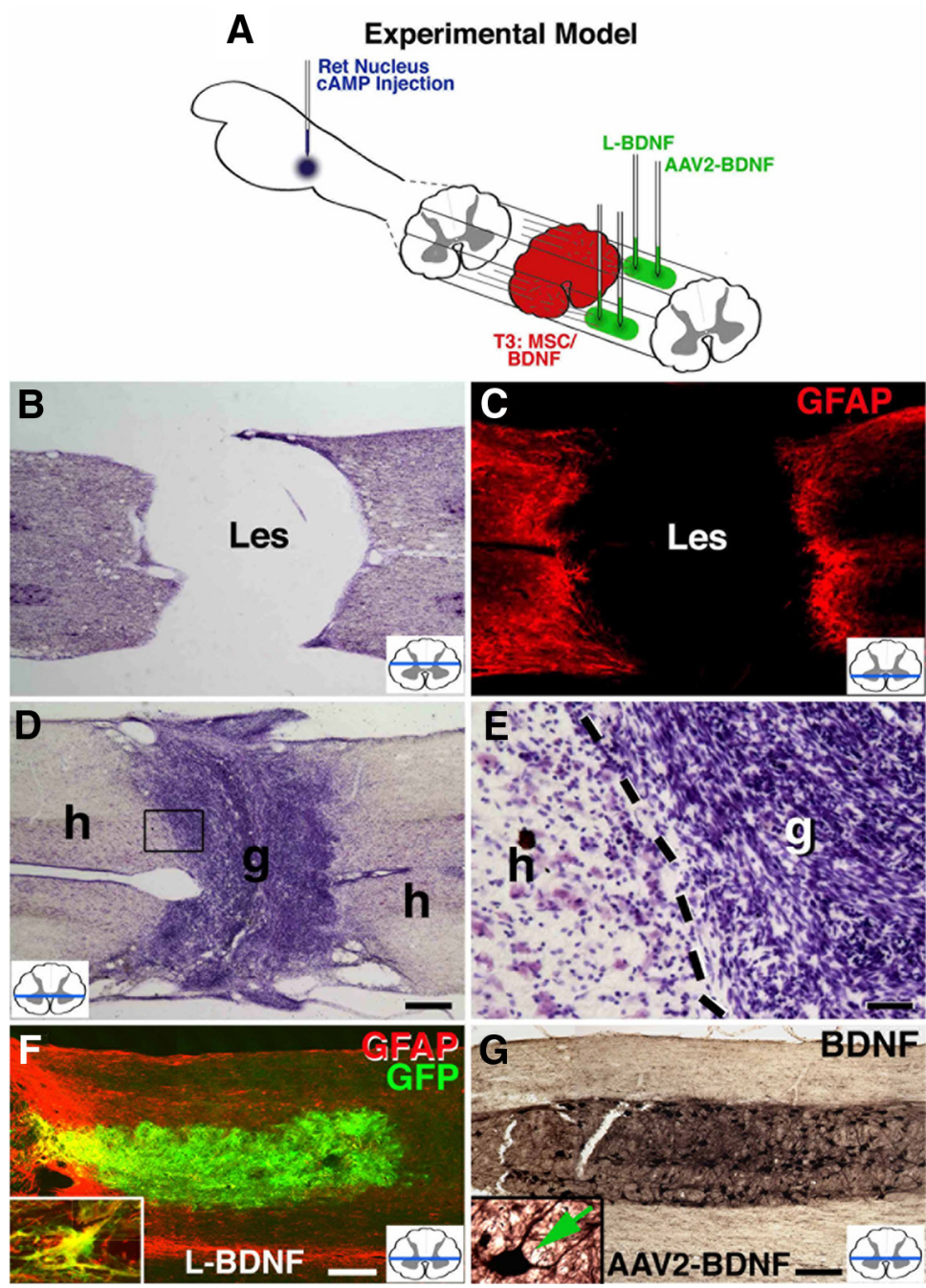

Figure 1. Experimental model, $T 3$ complete transection and graft morphology, and transduction of spinal cord cells by LentiBDNF or AAV2-BDNF vectors. $A$, Experimental model showing CAMP injection into reticular nucleus, graft of MSCs expressing BDNF $B$, Nissl staining of a horizontal spinal cord section showing completeness of T3 transection lesion (Les). The inset indicates level of orizontal section. C, The completeness of T3 transection lesion (Les) is indicated by GFAP fluorescent immunolabeling (Fig. 8). D boxed area of $\boldsymbol{D}$ showing excellent integration of MSC graft. The dashed lines indicate host $(\mathrm{h}) / \mathrm{graft}(\mathrm{g})$ interface. $\boldsymbol{F}$, Lentiviral (Lenti-BDNF-GFP) transduced mostly glia (GFAP-labeled astrocytes, red) (inset shows colocalization). $\mathbf{G}$, AAV2 vectors expressing BDNF-transduced cells with morphological features of neurons (inset). Scale bars: $\boldsymbol{B}-\boldsymbol{D}, 400 \mu \mathrm{m} ; \boldsymbol{E}, 120 \mu \mathrm{m} ; \boldsymbol{F}, \boldsymbol{G}$

Electron microscopy was performed according to the methods of Knott et al. (2009). Briefly, two rats with T3 complete transections that received combinatorial treatment were perfused with $4 \%$ paraformaldehyde and $0.25 \%$ glutaraldehyde (survival time, 3 months). Vibratome sections were cut at $40 \mu \mathrm{m}$ thickness and processed for light-level observation of BDA using DAB and nickel chloride. Regions of the host spinal cord containing BDA-labeled axons beyond the lesion were then microscopically dissected and postfixed with $1 \%$ osmium tetroxide, dehydrated, embedded in Durcupan resin. These samples were sectioned at 60 $\mathrm{nm}$ thickness using an ultramicrotome. Individual BDA-labeled axons or axonal terminals were located and assessed using an FEI 200KV Sphera microscope at the University of California at San Diego CryoElectron Microscopy Core Facility.

\section{Functional analysis}

In all studies, animals were handled and acclimated to the functional apparatus for 2 weeks before testing. For C5 hemisection studies, animals were assessed on grid walk, platform locomotion, and forelimb groom- 

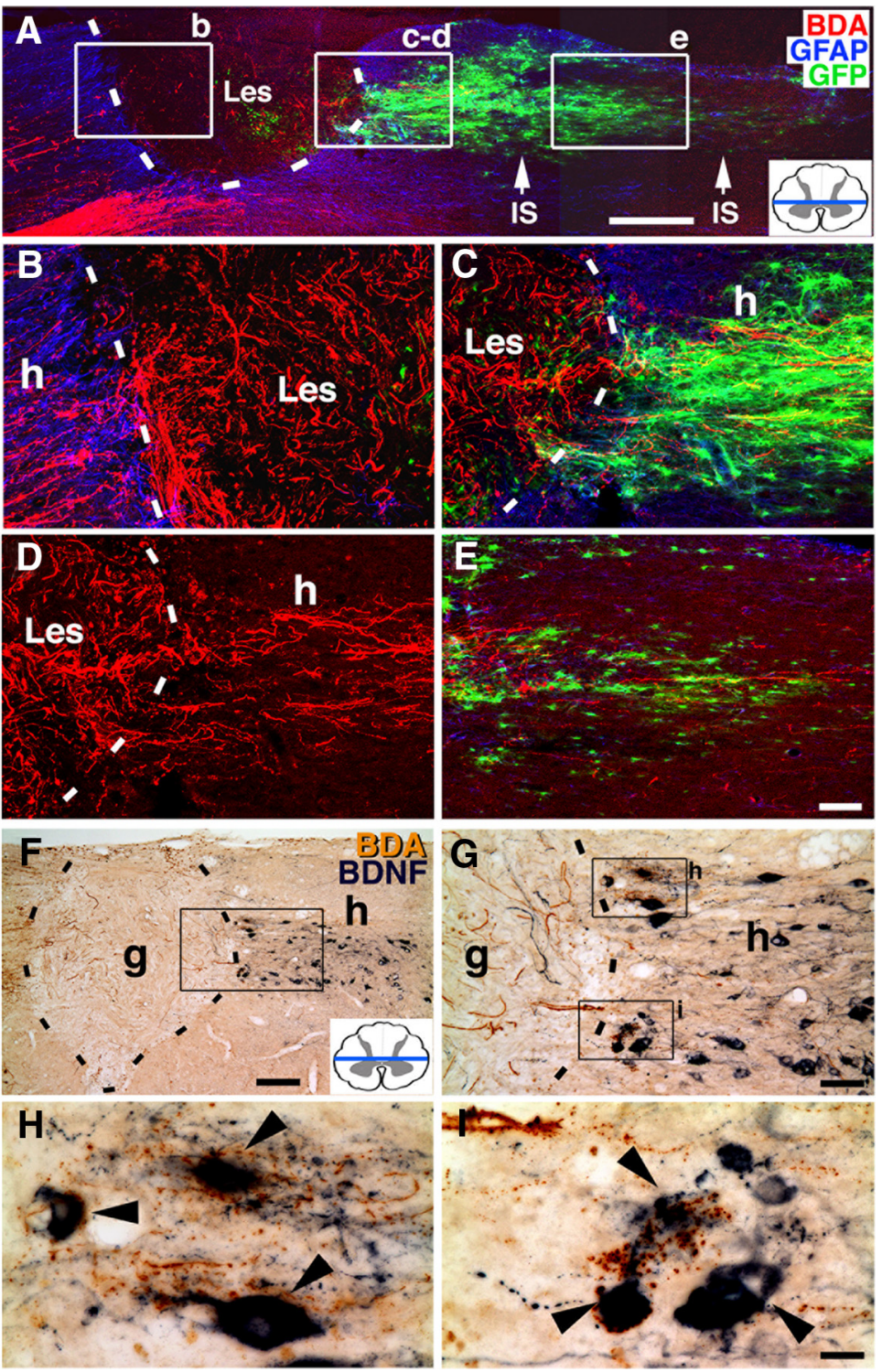

Figure 2. Motor axonal regeneration beyond spinal cord lesion sites. Transected reticulospinal motor axons regenerate into and beyond $C 5$ hemisection lesion site after combinatorial treatment with CAMP, a cell graft in the lesion site, and BDNF gradients beyond the lesion. $\boldsymbol{A}$, Triple label for BDA-labeled reticulospinal axons (red), host astrocytes (GFAP, blue), and host cells expressing BDNF (green, also expressing GFP) in a horizontal section at low magnification. Main reticulospinal tract approaches lesion (Les) from left side, extends into BDNF-expressing MSC graft, and some axons regenerate beyond the graft as highlighted in next panels. The arrows indicate viral vector injection sites (IS). $\boldsymbol{B}-\boldsymbol{D}$, Higher magnification from the boxed area in $\boldsymbol{A}$ showing axon regeneration (red) into MSC graft $(\boldsymbol{B})$, and axon crossing beyond lesion/graft site into caudal host tissue $(\boldsymbol{C}, \boldsymbol{D})$. The axons are present caudal to graft only in regions of BDNF expression (green). The dashed lines in $\boldsymbol{B}$ indicate rostral host (h)/lesion (Les) interface and in $\boldsymbol{C}-\boldsymbol{E}$ indicate caudal lesion/host interface. $\boldsymbol{E}$, Growth of presumably bridging axons (red) into caudal host tissue is exclusively in regions of BDNF expression (green). $\boldsymbol{F}$, The association of regenerating axons with BDNF expression is also revealed by double light-leve immunolabeling for BDNF (dark blue) and BDA (brown): BDA-labeled reticulospinal axons regenerate into the lesion/graft (g) site and extend into caudal host (h) spinal cord gray matter expressing BDNF. The graft is outlined by the dashed lines. $\mathbf{G}$, High magnification of the boxed area from $\boldsymbol{F}$ shows BDA-labeled axons crossing caudal graft/host interface (dashed lines). $\boldsymbol{H}, \boldsymbol{I}$, Higher magnification from boxed areas of $\boldsymbol{G}$ show clusters of BDA-labeled reticulospinal axons (brown, arrowheads) closely associating with BDNF-expressing host neurons (dark blue). Scale bars: $\boldsymbol{A}, 530 \mu \mathrm{m} ; \boldsymbol{B}-\boldsymbol{E}, 95 \mu \mathrm{m} ; \boldsymbol{F}, 280 \mu \mathrm{m} ; \boldsymbol{G}, 50 \mu \mathrm{m} ; \boldsymbol{H}, \boldsymbol{I}, 20 \mu \mathrm{m}$.

ing tasks (Basso et al., 1996; Gensel et al., 2006; Sandrow et al., 2008). Baseline scores were established before lesion and were measured weekly for 3 months after lesion.

Grid walk task. Footfalls were measured as animals walked on a 38 $\mathrm{cm}^{2}$ plastic-coated wire mesh field containing $3 \mathrm{~cm}^{2}$ openings, in 2 min test sessions recorded on video (Sandrow et al., 2008). Each forepaw was scored for the total number of steps and the total number of missteps. The total number of steps and missteps were added together to obtain the total number of placements. The percentage injured right forepaw correct placement was calculated by dividing the number of steps by the total number of placements (steps plus missteps).

Grooming task. Forelimb grooming function was examined using a scoring system modified by Gensel et al. (2006). Briefly, cool tap water was applied to the animal's head and back with soft gauze, and grooming activity was recorded with a video camera. Subjects were scored for the regions of the head contacted by each forepaw during grooming, as reported previously (Gensel et al., 2006). The grooming scoring system is as follows: 0 , the animal was unable to contact any part of the face or head; 1 , the animal's forepaw touched the underside of the chin and/or the mouth area; 2, the animal's forepaw contacted the area between the nose and the eyes, but not the eyes; 3, the animal's forepaw contacted the eyes and the area up to, but not including, the front of the ears; 4 , the animal's forepaw contacted the front but not the back of the ears; 5 , the animal's forepaw contacted the area of the head behind the ears. Performance was reported as score on the lesioned versus the intact side (right score/left score).

Kinematics. Hip and forepaw movements during voluntary locomotion on a platform were measured. Rats walked through a Plexiglas tunnel to encourage walking in a twodimensional plane and to maintain constancy of distance from subject to camera. Movements were filmed with two horizontal cameras (right and left sides) and tracked using a combination of Datapac 5 (Run Technologies) and Simi Motion (SIMI Reality Motion Systems) software. Simi Motion was used to calculate the distance between the hips and forepaws throughout walking episodes, and Datapac was used to measure step trajectories. Kinematic data were taken from the middle of walking episodes. For T3 complete transection studies, function was assessed on the Beattie-Basso-Bresnahan (BBB) 21-point hindlimb locomotor rating scale by two observers blinded to group identity, as previously described (Basso et al., 1996). To assess whether any differences in function were attributable to host axons regenerating into and beyond the graft, after the final day of testing, rats underwent spinal cord retransection at the rostral graft/host interface, and were reassessed in a final behavioral session $1 \mathrm{~d}$ later. If functional improvement was due to axonal bridging, we would expect functional improvements to be abolished after retransection; if, however, functional improvement was due to trophic factor secretion from grafts or BDNF injected beyond the lesion site, functional improvement could be unaffected by the lesion.

When results of the preceding studies became evident, we performed S2 complete transections in a set of nine additional rats to assess spasticity; this model is the only semiquantitative model of this disorder, an important sequel of spinal cord injury (Bennett et al., 2004; Murray et al., 2010). Under sodium pentobarbital $(58.5 \mathrm{mg} / \mathrm{kg})$ and sterile conditions, a laminectomy was performed at L2 to expose the S2 spinal cord. Under a surgical microscope, the spinal cord was transected with visual verification of lesion completeness ventrally and laterally. One microliter of 

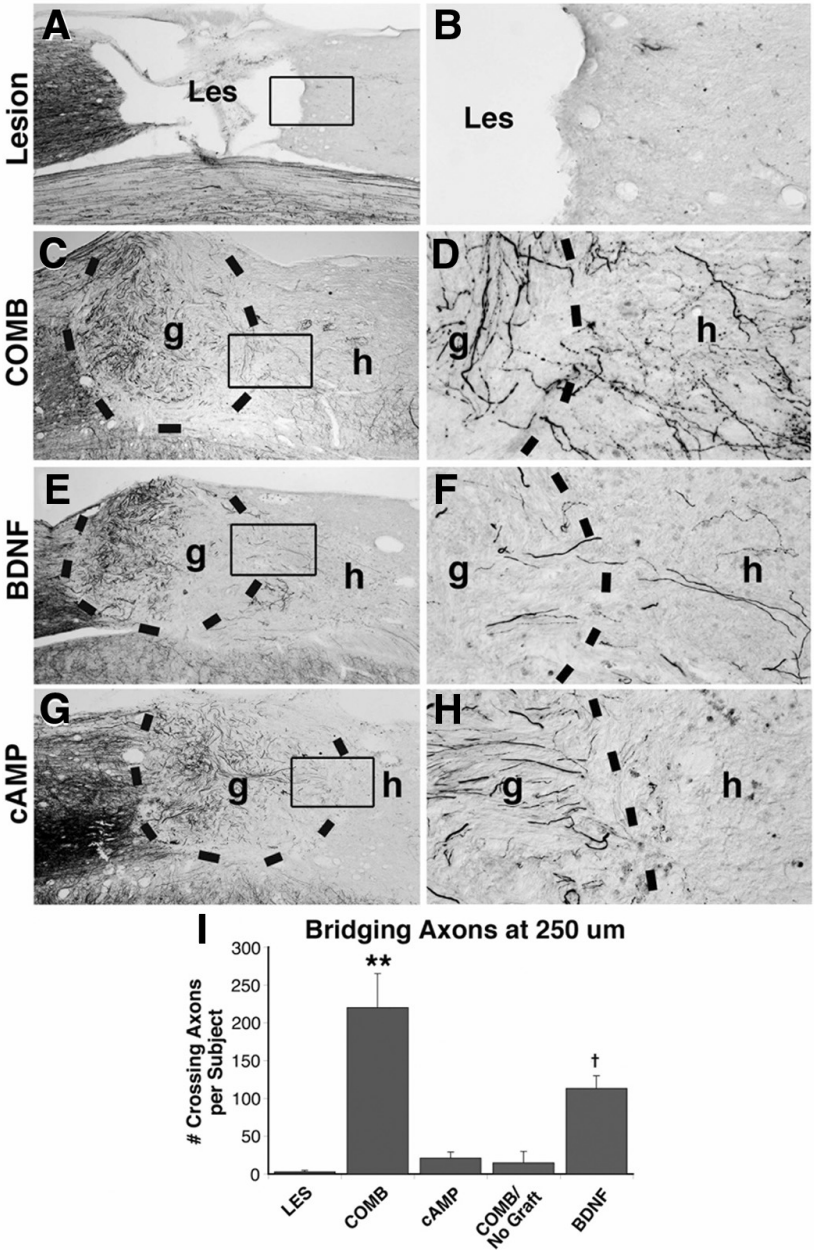

Figure 3. Reticulospinal axon growth in controls: quantification. BDA light-level immunolabeling in four experimental groups. $A, B$, Lesioned control: Axons do not penetrate the lesion cavity in the absence of a cell graft, and few axons are present at the caudal lesion/host interface (B) (higher magnification of $\boldsymbol{A}$ ). C, D, Combination treatment: Reticulospinal axons robustly regenerate into the marrow stromal cell graft in the lesion site and appear to cross the distal graft/host interface $(\boldsymbol{D})$. The dashed lines indicate host (h)/graft (g) interface. $\boldsymbol{E}, \boldsymbol{F}, \mathrm{BDNF}$ treatment: Axons also penetrate marrow stromal cell graft in lesion site $(\boldsymbol{E})$ and appear to emerge distally $(\boldsymbol{F})$. cAMP was not injected into pons; number of axons regenerating beyond lesion is reduced compared with combination treatment, quantified in $\boldsymbol{I} . \mathbf{G}, \boldsymbol{H}$, CAMP treatment: Axons penetrate graft in lesion site $(\boldsymbol{G})$, but do not appear to regenerate beyond lesion $(\boldsymbol{H})$. BDNF was not provided. Scale bars: $\boldsymbol{A}, \boldsymbol{C}, \boldsymbol{E}, \boldsymbol{G}, 300 \mu \mathrm{m} ; \boldsymbol{B}, \boldsymbol{D}, \boldsymbol{F}, \boldsymbol{H}, 60 \mu \mathrm{m}$. I, Quantification of number of BDA-labeled axons crossing a vertical line placed $250 \mu \mathrm{m}$ beyond distal graft/host interface reveals significant overall group differences (ANOVA, $p<0.01$ ). Significantly greater numbers of axons regenerate beyond graft in combination group (COMB) than all other groups ( post hoc Fisher's compared with BDNF group, $p<0.05$; compared with each other group, ${ }^{* *} p<0.01$ ). BDNF treatment alone also differs from other groups ( ${ }^{\dagger} p<0.05$ in each case). Error bars indicate SEM.

AAV2-BDNF $\left(2 \times 10^{12} \mathrm{vg} / \mathrm{ml} ; n=5\right)$ or, in controls, AAV2-GFP $(2.5 \times$ $\left.10^{12} \mathrm{vg} / \mathrm{ml} ; n=4\right)$ was slowly injected into the S2 spinal cord below the transection, as described above. Four weeks later, spasticity was assessed: with rats in a Plexiglas tube and tail protruding from one end (free to hang vertically), the tail was stimulated with a brief standardized stretch/ rub maneuver as previously described (Bennett et al., 2004). The degree of subsequent coiling of the tail was rated on a graded 5-point scale (Bennett et al., 2004) as follows: 0, only slight tail flick in response to stretch, and otherwise unresponsive to stimulation or touch; 1 , weak flexion coiling of the tip of the tail in response to stretch/rub $\left(90^{\circ}\right.$ and lasting only $\sim 1 \mathrm{~s}$ ), little or no muscle tone, no clonus, no response to light touch of skin or hairs; 2 , moderate flexion coiling of the whole tail in response to stretch rub, with maximum excursions of $90-180^{\circ}$, lasting
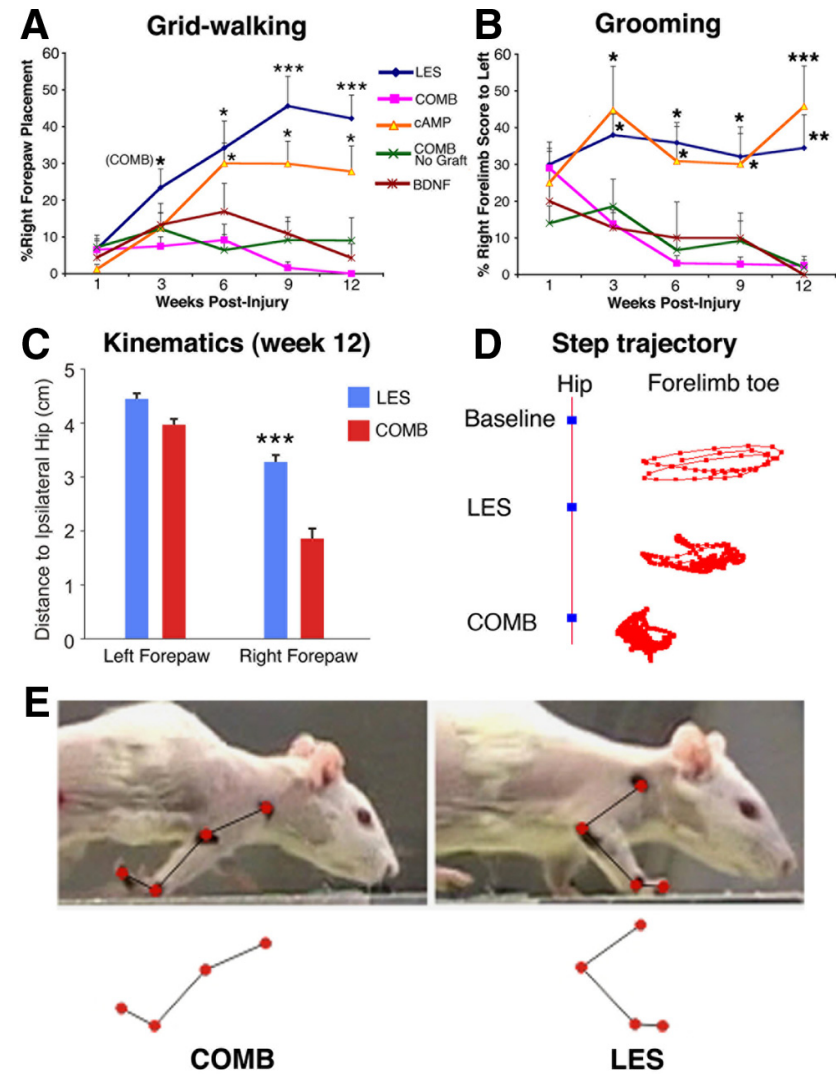

Figure 4. Motor outcomes worsen in BDNF recipients. Functional outcomes were measured on three tasks after $C 5$ hemisection: grid walking, grooming, and gait kinematics. $A$, Functional outcomes on the grid-walking task are worse than lesioned controls in each group that received BDNF (COMB and BDNF). Lesioned groups lacking BDNF below the lesion exhibited significant improvement of right forelimb placement over time [multivariate ANOVA (MANOVA) repeated measures, between groups, $p<0.0001$; time, $p<0.0001$; time by group, $p<0.001$; ${ }^{*} p<$ $0.05 ;{ }^{* * *} p<0.001 ; N=12$ each group] [the asterisk $\left({ }^{*}\right)$ in COMB dataset indicates significant difference between COMB and LES group]. $B$, Similar recovery patterns, and deficits in recovery in BDNF recipients, were observed in forelimb use on the grooming task (MANOVA with repeated measures, between groups, $p<0.01$; time, $p<0.23$; time by group, $p<0.05$; ${ }^{*} p<$ $\left.0.05,{ }^{* *} p<0.01,{ }^{* * *} p<0.001\right)$. C, Kinematic analysis of forepaw placement during locomotion shows significant reduction in distance from right forepaw to hip in the combination treatment group (COMB) compared with the lesion-only control (LES) $\left.{ }^{* * *} p<0.001\right)$. There are no significant differences in the intact left forepaw, 12 weeks after injury. Error bars indicate SEM. D, Examples of a typical right forepaw step trajectory relative to ipsilateral hip position (blue square) in an intact (baseline), lesion-only (LES), and combinatorial treatment (COMB) subjects. There is less joint excursion and reduced overall recovery in step trajectory in the treatment group, likely reflecting spasticity. $E$, Static images and tracings (below) of joints from video illustrating the right forepaw (arrow) in a retroflexed, grasp posture in a COMB-treated subject, compared with a nongrasp posture in a LES control.

$\sim 3$ s each; 3, strong flexor direction coiling spasms of whole tail in response to stretch/rub, with maximum excursions of $180-360^{\circ}$ in the tip of the tail and lasting 3-10 s each; repeated flexion spasms (coiling) and clonus lasting $\sim 10 \mathrm{~min}$ after stretch/rub; hypertonus; very sensitive to light touch and withdrawal to even touch of a single hair; 4 , similar to previous rating (3), but with extensor as well as flexor coiling spasms and responses to stretch/rub, so that the tail often obtained an S-shape with the proximal portion flexing under the rat, and the distal portion extending in the opposite direction; also, greater clonus, hypertonus, and sideto-side whipping present. Following scoring, a decimal was added to reflect the duration and intensity of the spasm. For functional testing, observations were made by two individuals who were different from the surgeons and were blinded to group identity, and scores were averaged for subsequent statistical analysis. 

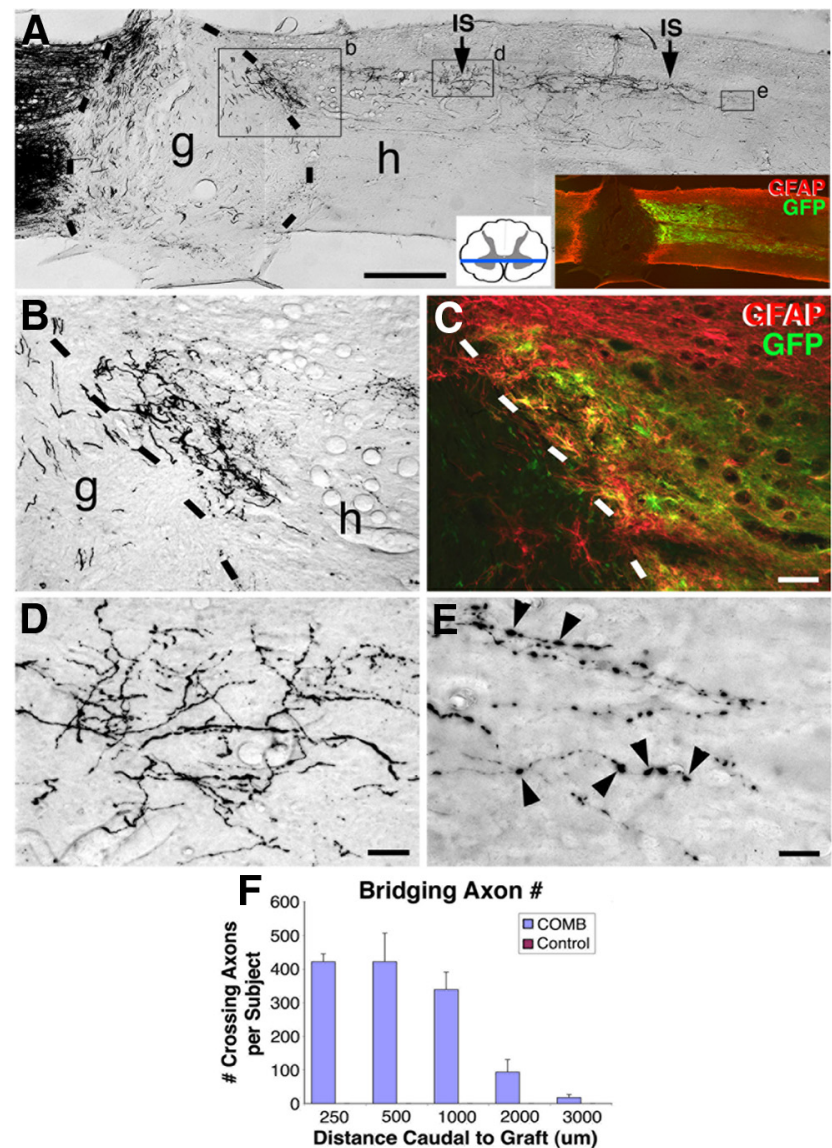

Figure 5. Combinatorial treatments promote motor axonal regeneration beyond sites of complete spinal cord transection. A combination of CAMP and BDNF supports reticulospinal motor axon regeneration beyond $\mathrm{T} 3$ complete transection. $A$, Overview of complete transection site (horizontal section) showing BDA-labeled reticulospinal axons approaching lesion site (left side), regenerating into graft $(\mathrm{g})$, and regenerating beyond lesion into caudal host (h) spinal cord. IS, Injection sites of BDNF-expressing vectors. $\boldsymbol{B}$, Higher magnification of indicated region from $\boldsymbol{A}$, demonstrating BDA-labeled reticulospinal axons crossing caudal graft/host interface (dashed lines) into distal spinal cord. C, Axons regenerate beyond lesion site only into regions that express BDNF, indicated by GFP reporter gene expression in the same section shown in $\boldsymbol{B}$. GFAP labeling, Red. $\boldsymbol{D}, \boldsymbol{E}$, Clusters of bridging axons $(\boldsymbol{D})$ and axons with varicosities $(\boldsymbol{E})$ can be found up to $4 \mathrm{~mm}$ caudal to lesion site in host cord, in regions of BDNF expression. Scale bars: $A$, $600 \mu \mathrm{m} ; \boldsymbol{B}, \boldsymbol{C}, 88 \mu \mathrm{m} ; \boldsymbol{D}, 44 \mu \mathrm{m} ; \boldsymbol{E}, 15 \mu \mathrm{m}$. $\boldsymbol{F}$, Quantification of axons bridging across T3 complete transection after combinatorial treatment $(n=6)$. The number of axons crossing a virtual line $250,500,1000,2000$, and $3000 \mu \mathrm{m}$ beyond the lesion site was quantified. Axons are not detectable beyond the lesion in controls with lesions alone $(N=6)$. Error bars indicate SEM.

Statistics

Multiple-group comparisons were assessed by ANOVA with a significance criterion of $95 \%$. Post hoc differences were tested by Fisher's leastsquare difference. When two groups were being compared, differences were assessed by two-tailed Student's $t$ test. Observers were blinded to group identity in all assessments, as noted above.

\section{Results}

Graft survival and gene expression

In all grafted subjects in both $\mathrm{C} 5$ hemisection and $\mathrm{T} 3$ transection groups, marrow stromal cells survived well and filled the lesion cavity (Fig. 1D,E). Cystic cavitation occurred in nongrafted controls (Fig. $1 B, C$ ). Gene expression continued throughout the 3 month experimental period, evidenced both by expression of the GFP reporter (Figs. $1 F, 2 A, C, E$ ) and BDNF (Figs. $1 G, 2 F-I$ ) within ventral gray matter below lesion. BDA-labeled host reticulospinal axons in both $\mathrm{C} 5$ and $\mathrm{T} 3$ injury models grew into the
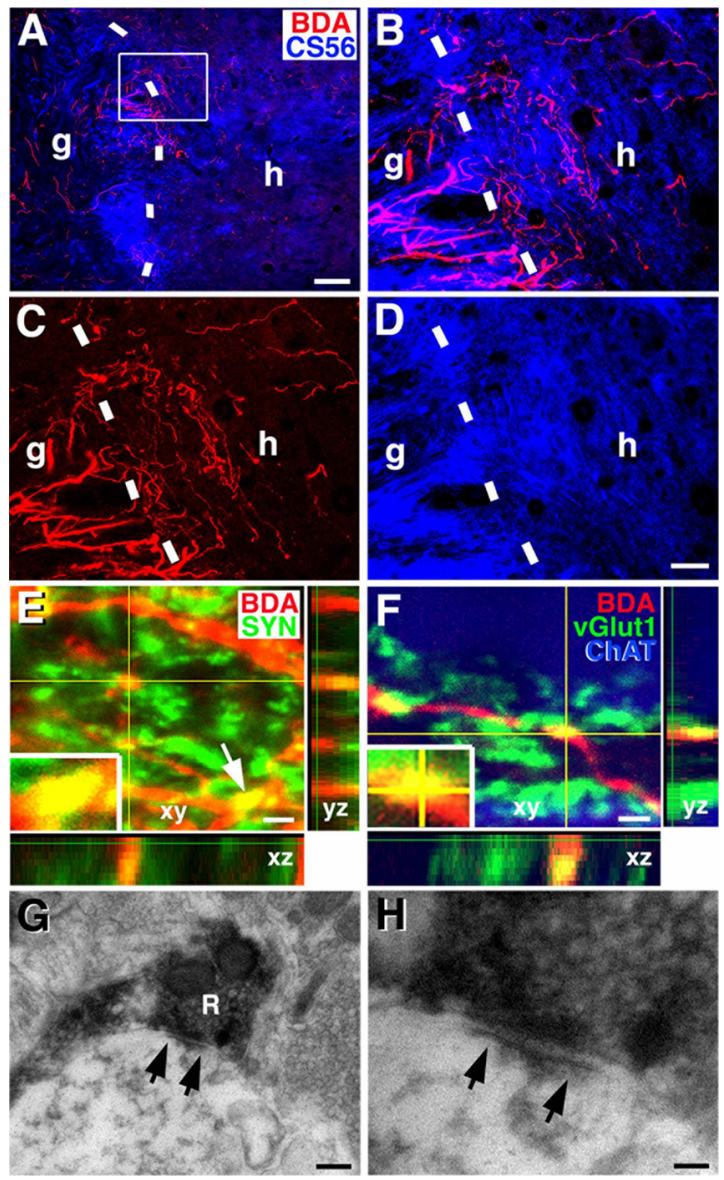

Figure 6. Regenerating reticulospinal axons extend through glial scars and form distal synapses after T3 complete transection. A, BDA and CS56 double immunolabeling in a horizontal section demonstrates that BDA-labeled reticulospinal axons bridge through regions of chondroitin sulfate proteoglycan labeling (CS56 antibody), at caudal graft $(\mathrm{g}) / \mathrm{host}(\mathrm{h})$ interface (dashed lines) 3 months after T3 complete transection. $\boldsymbol{B}-\boldsymbol{D}$, Higher magnification view of the boxed area from $\boldsymbol{A}$ shows merged $(\boldsymbol{B})$ and individual channels $(\boldsymbol{C}, \boldsymbol{D})$. $\boldsymbol{E}$, Two millimeters caudal to $\mathrm{T} 3$ complete transection, BDA-labeled reticulospinal axons (red) colocalize with the presynaptic marker synaptophysin (SYN) (green), confirmed in $x z$ and $y z$ plane reconstructions. A sample putative synapse in the bottom right corner of the panel (arrow) is shown in the inset. $\boldsymbol{F}$, Regenerating reticulospinal axons (red) express VGlut1 (green) in juxtaposition to a motor neuron labeled for ChAT (blue), suggesting that regenerating axons resume expression of an appropriate, excitatory neurotransmitter. $\boldsymbol{G}, \boldsymbol{H}$, Immunoelectron microscopy confirms that regenerating, BDA-containing reticulospinal axons ( $R$, dark reaction product of BDA) form synapses (arrows) with that host dendrites located $2 \mathrm{~mm}$ below the lesion. Scale bars: $\boldsymbol{A}, 125 \mu \mathrm{m}$; $B-D, 32 \mu \mathrm{m} ; \boldsymbol{E}, 2 \mu \mathrm{m} ; \boldsymbol{F}, 1.8 \mu \mathrm{m} ; \boldsymbol{G}, 150 \mathrm{~nm} ; \boldsymbol{H}, 50 \mathrm{~nm}$.

lesion site only among subjects that received marrow stromal cell grafts (Figs. 2, 3, 5).

\section{C5 hemisection model: combinatorial treatments promote} regeneration of brainstem motor axons into and beyond lesion sites

The greatest degree of regeneration of brainstem reticulospinal motor axons into and beyond the lesion site after C5 hemisection occurred among subjects that received full combinatorial therapy with a cell bridge in the lesion site, BDNF expression within and below the lesion site, and cAMP injection into the brainstem (ANOVA, $p<0.05$; Figs. 2, 3; quantified in Fig. 3I). While subjects that received BDNF treatment alone also exhibited some bridging axons, combinatorially treated animals exhibited $60 \%$ more axons regener- 

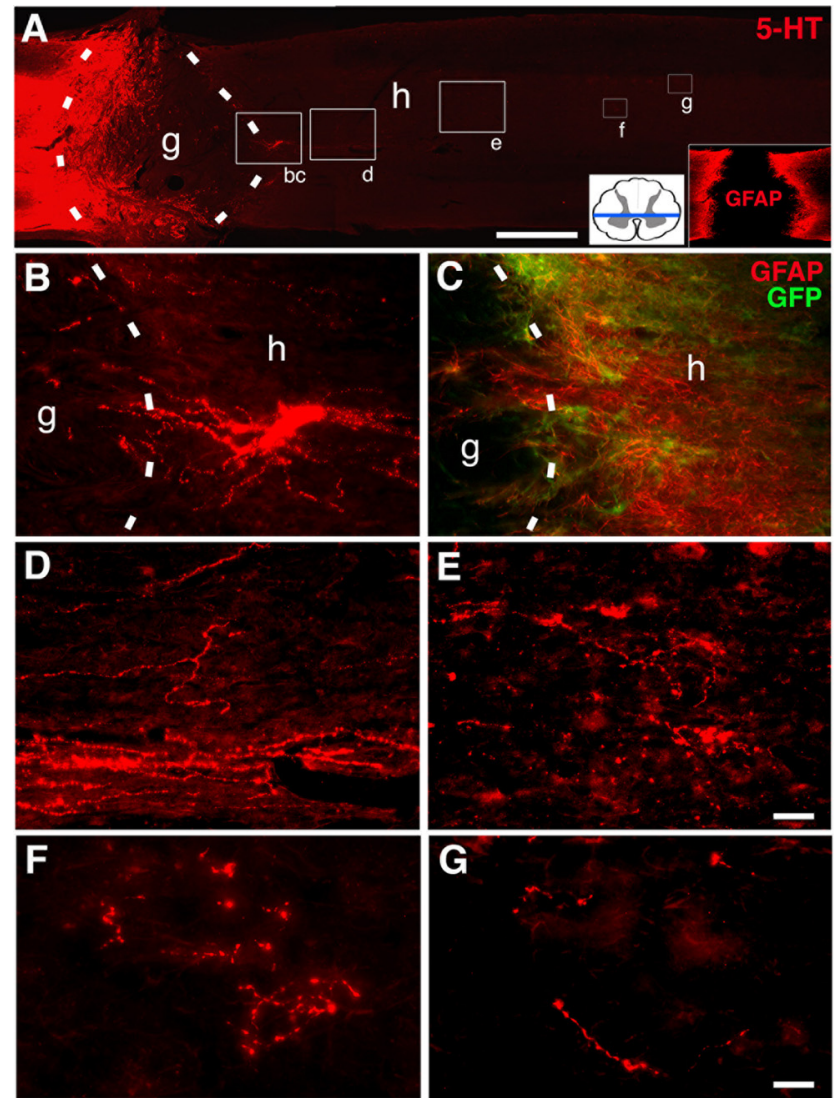

Figure 7. Combinatorial treatments promote serotonergic motor axonal regeneration beyond sites of T3 complete transection. $\boldsymbol{A}$, Low magnification of a horizontal spinal cord section showing 5-HT-labeled raphespinal axons (red) approaching the lesion from the rostral (left) side, regenerating into the graft in the lesion site, and beyond. The dashed lines indicate rostral and caudal interfaces. The inset is GFAP label showing lesion site. $\boldsymbol{B}$, Higher magnification of the boxed area from $\boldsymbol{A}$, demonstrating raphespinal axons crossing caudal graft $(\mathrm{g}) /$ host $(\mathrm{h})$ interface (dashed lines). $\boldsymbol{C}$, Same section as $\boldsymbol{B}$ now labeled for GFAP (red as pseudocolor) to show lesion border and GFP expression: serotonergic axons regenerate only into regions expressing BDNF. D-G, Clusters of serotonergic axons regenerating up to $4 \mathrm{~mm}$ caudal to lesion site. Scale bars: $\boldsymbol{A}, 800 \mu \mathrm{m} ; \boldsymbol{B}-\boldsymbol{E}, 64 \mu \mathrm{m} ; \boldsymbol{F}, \boldsymbol{G}, 20 \mu \mathrm{m}$.

ating beyond the lesion ( $p<0.001$, post hoc Fisher's compared with full combination treatment).

Axon bundles crossed the caudal host/graft interface in combination treatment and BDNF-treated animals, and extended toward regions of peak BDNF expression (Fig. 2). Indeed, axons did not bridge beyond the distal host/graft interface unless BDNF gene expression from viral vector injections extended immediately up to the caudal host/graft interface, indicated by GFP reporter expression (Fig. 2A,C,E) and BDNF immunolabeling (Fig. $2 F-I$ ). Moreover, bridging axons were only present within regions of BDNF expression (Fig. 2), indicating that bridging motor axons follow chemotropic gradients of growth factors. BDA-labeled axons extending caudal to the graft often exhibited circuitous trajectories and emerged from all regions of grafts, rather than only the most ventral or dorsal aspects of the lesion site where spared axons might be located. These observations support the probability that the observed axonal profiles represented newly regenerated rather than spared axons.

Functional assessment was performed at intervals of 1, 3, 6, 9, and 12 weeks after injury in C5 hemisection lesion subjects. Notably, all groups that received BDNF treatment within and below the lesion exhibited significantly worse functional outcomes than control-lesioned rats, despite the presence of axons regenerating

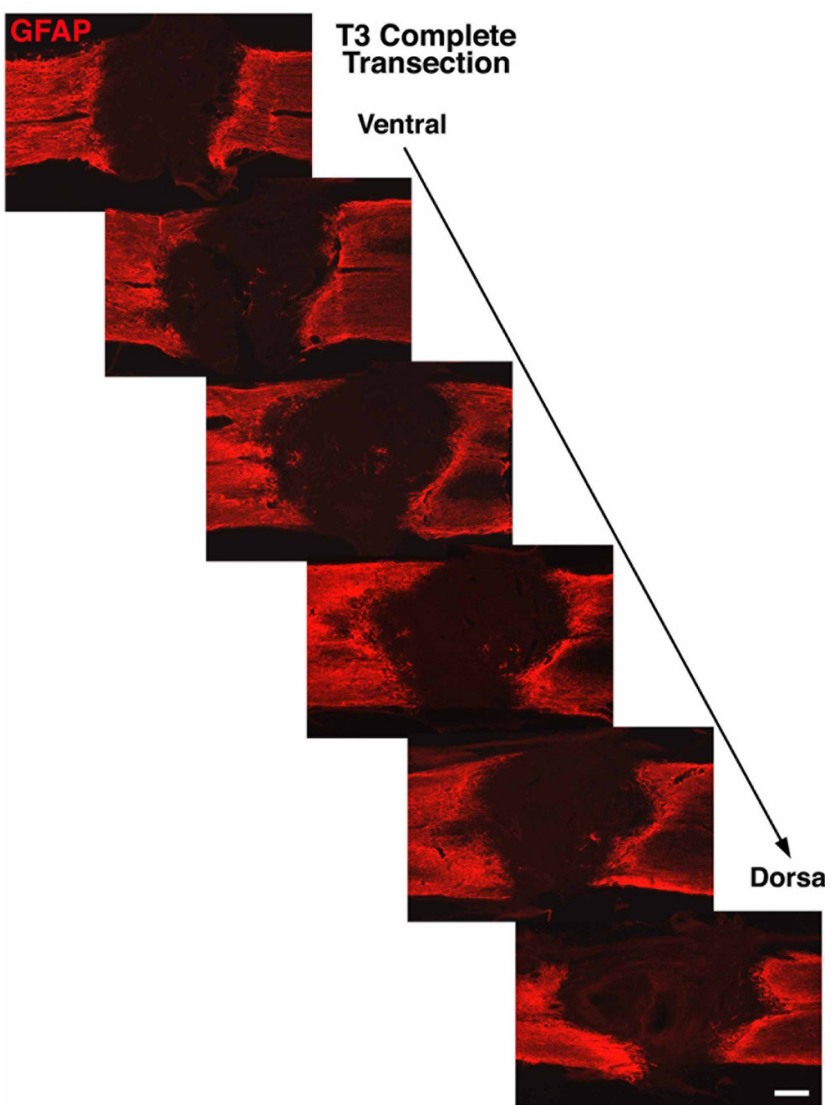

Figure 8. Completeness of T3 complete transection. GFAP immunolabeling from a series of every sixth horizontal section demonstrates completeness of T3 complete transection from ventral through dorsal spinal cord. Scale bar, $125 \mu \mathrm{m}$.

below the lesion in treated versus control subjects $(p<0.05$ ANOVA, post hoc Fisher's comparing BDNF-treated subjects to lesioned controls, $p<0.05$; Fig. 4). Qualitative assessment of limb tone in all BDNF-treated subjects revealed spasticity on range of motion of the lesioned side; this finding was confirmed quantitatively in subjects with complete spinal transections (below). Moreover, BDNF-treated subjects exhibited spontaneous clonic limb movements of the affected forelimbs and hindlimbs upon limb placement onto a flat surface, suggesting activated local spinal reflex activity, similar to that observed in humans after spinal cord injury (Hubli et al., 2011).

Histological sectioning of the brainstem confirmed that cAMP injections were accurately targeted to paragigantocellular pontine nucleus reticular neurons, and that injections did not cause damage (data not shown).

While brainstem reticulospinal motor axons regenerated below the caudal lesion/host interface (Figs. 2, 3), it remains possible that reticulospinal axons on the contralateral, intact side of the spinal cord decussated below the lesion site and entered the graft from below the lesion site, traveling in a caudal-to-rostral direction rather than truly bridging beyond the lesion site from rostral levels. This is unlikely because the density of BDA-labeled reticulospinal axons was greater within the graft than caudal to the graft. Nonetheless, proof of motor axonal regeneration into and beyond the lesion site requires complete spinal cord transection. We accordingly next tested whether the optimal full combination treatment identified in the $\mathrm{C} 5$ hemisection model would achieve axonal regeneration into and beyond a site of complete 
T3 transection. Comparison was made to control rats that underwent $\mathrm{T} 3$ transection alone.

\section{T3 complete transection: combinatorial treatments promote bridging regeneration of brainstem motor axons}

Subjects that received full combination treatment with cell grafts, cAMP injections into the pontine reticular nucleus, and growth factor gradients within and beyond the lesion site, exhibited axonal regeneration across sites of complete thoracic spinal cord transection. Growth of some axons continued for up to $4 \mathrm{~mm}$ caudal to the distal border of the lesion, reaching the caudal site of growth factor injection, as shown and quantified in Figure 5. Regenerating axons crossed glial interfaces and sites of chondroitin sulfate proteoglycan deposition (CS56 label; Fig. 6) to penetrate the host spinal cord beyond the lesion. Again, axons bridged beyond the lesion only when regions of growth factor expression immediately abutted the graft/lesion site (indicated by expression of the reporter gene GFP; Fig. 5C). Furthermore, the regeneration of host axons was entirely restricted to regions of BDNF expression, indicating that regenerating axons exhibit chemotropic attraction and guidance to the growth factor.

BDA-labeled reticulospinal axons regenerated beyond the lesion site into regions of $\alpha$ motor neuronal cell bodies (labeled with choline acetyltransferase; Fig. $6 F$ ). These regenerating axons colocalized with the presynaptic marker synaptophysin on highresolution confocal imaging, indicating likely formation of synapses (Fig. 6E). Moreover, these regenerating reticulospinal axons expressed VGlut1, suggesting formation of appropriate excitatory synapses (Fig. 6F). Synapse formation by regenerating brainstem motor axons was confirmed on ultrastructural analysis, with BDA-dense reticulospinal axon terminals forming synapses with host dendrites (Fig. 6G,H).

Raphespinal projections to the spinal cord modulate spinal motor activity (Sillar et al., 1995), and these axons have previously been reported to exhibit sensitivity to BDNF (Xu et al., 1995; Jin et al., 2000; Lu et al., 2003). We accordingly examined responses of raphespinal axons to combination therapies using serotonin immunolabeling. As observed with reticulospinal projections, raphespinal axons regenerated across sites of complete T3 transections (Fig. 7). 5-HT-labeled axons clearly crossed the caudal graft/host interface (Fig. 7), and the density of bridging axons progressively diminished over greater distances beyond the lesion site, indicating that the 5-HT label was not merely detecting a possible resident spinal cord population of serotonergic neurons. Axons were present up to $4 \mathrm{~mm}$ caudal to the graft/host interface, but not beyond, corresponding to the most caudal site of growth factor expression.

Serial sectioning of the spinal cord established lesion completeness in all subjects (Fig. 8). Moreover, regenerating axons exited from the midportions of grafts, not merely from the most ventral, lateral, or dorsal aspects of the lesion site where spared axons might be located and mistaken for regenerating axons. Finally, regenerating axons exhibited circuitous trajectories and irregular morphologies, suggesting newly regenerating axons rather than spared axons. This evidence strongly supports the conclusion that true axonal bridging across sites of complete spinal cord transection can be achieved after complete spinal cord injury.

\section{Myelination of regenerating motor axons}

In sensory systems, we have found that axons regenerating rostral to a high cervical lesion site do not become remyelinated (Alto et al., 2009), a finding that may limit functional recovery. In the

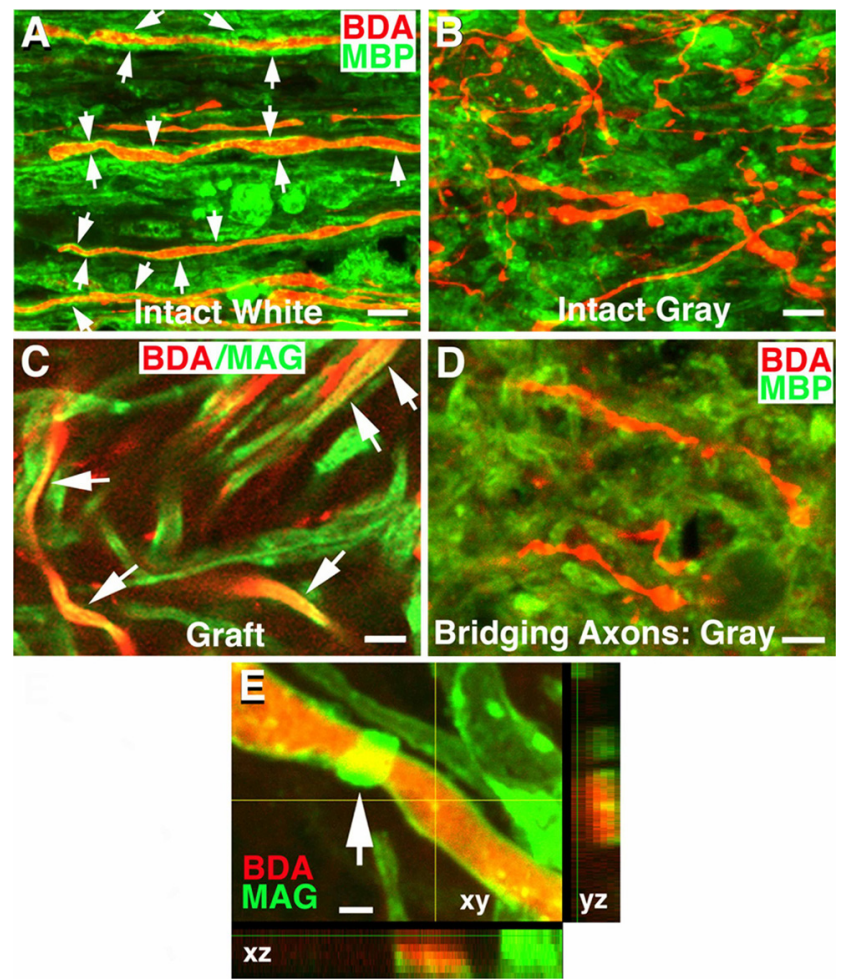

Figure 9. Myelination of regenerating axons. Intact reticulospinal axons in white matter (A) are normally myelinated (arrows) but lose their myelin sheaths upon entering gray matter (B). BDA (red) and MBP (green) double labeling is shown. $C$, Upon regenerating into a marrow stromal cell graft in the lesion cavity, most axons are remyelinated (MAG label, arrows) by Schwann cells migrating into the lesion site (Jones et al., 2003; Lu et al., 2005; Alto et al., 2009). D, Reticulospinal axons that regenerate beyond the T3 complete transection site, into gray matter, are not myelinated and resemble gray matter axon terminals on intact animals, as seen in $\boldsymbol{B}$. $\boldsymbol{E}$, Higher magnification image of a myelinated axon in a graft (arrow points to a node of Ranvier). Scale bars: $\boldsymbol{A}, 7 \mu \mathrm{m} ; \boldsymbol{B}, \mathbf{D}, 6 \mu \mathrm{m} ; \boldsymbol{C}, 12 \mu \mathrm{m} ; \boldsymbol{E}, 2.5 \mu \mathrm{m}$.

present experiments, the relevance of remyelination depends on the regenerating axonal system: serotonergic axons in the spinal cord are normally sparsely myelinated if at all (Basbaum et al., 1988), whereas reticulospinal axons are predominantly myelinated (Loy et al., 2002). Yet reticulospinal axons normally lose their myelin sheaths upon reaching neuronal targets in spinal gray matter, a finding we confirmed in this experiment using double labeling for MAG or MBP and BDA-labeled reticulospinal axons above the lesion site (Fig. 9A,B): $81 \pm 1.5 \%$ of BDAlabeled axons in white matter $3 \mathrm{~mm}$ above the lesion were myelinated, whereas only $8.2 \pm 0.8 \%$ of BDA-labeled axons in gray matter $3 \mathrm{~mm}$ above the lesion were myelinated. Thus, while remyelination of regenerating reticulospinal axons within the graft may be necessary to recapitulate the preinjury state, it need not be the case that reticulospinal axons must be myelinated upon penetrating host gray matter below the lesion where potential target neurons are present. Double labeling for regenerating axons and myelin showed that reticulospinal axons were indeed frequently remyelinated within grafts in the lesion site (71.7 \pm $4.6 \%$ of sampled axons; Fig. $9 C, E)$ but were not myelinated in host gray matter beyond the lesion (Fig. 9D). Host Schwann cells have previously been shown to migrate into lesion sites and to remyelinate regenerating axons in cell grafts (Jones et al., 2003; Lu et al., 2005; Alto et al., 2009).

\section{Functional outcomes}

Locomotor outcomes were assessed on the BBB scale after complete T3 transection (Basso et al., 1996). Combination-treated 
subjects exhibited significant improvements in the BBB scale compared with controls $(p<0.05$; Fig. $10 A)$; however, all treated animals exhibited readily detectable lower limb spasticity, reflected as resistance to passive range of motion of the lower limbs, particularly in extensor muscles. Subjects also exhibited spontaneous clonic movements of the hindlimbs upon contact with a flat surface, as observed in subjects with C5 hemisections (above). Importantly, spinal retransection after recovery in the treated group failed to significantly reduce $\mathrm{BBB}$ scores (Fig. 10A); moreover, lower limb spasticity and clonic movements on contact placement persisted. These findings suggest that hyperactivity of local spinal circuitry within the spinal cord below the transection site generated higher BBB scores in the treated group. Thus, assessment of functional effects of motor axons regenerating below the lesion site was potentially masked by activation of spinal reflex activity and spasticity, an effect likely due to persistent BDNF expression (Boulenguez et al., 2010). We confirmed that BDNF induces spasticity in a validated, quantitative model of lower limb spasticity (Murray et al., 2010). To assess spasticity, nine additional rats underwent S2 complete spinal cord transection and injection of AAV2-

$\operatorname{BDNF}(n=5)$ into the spinal cord caudal to the lesion, and were compared with control subjects with AAV2-GFP injections $(n=$ $4)$. BDNF-treated subjects exhibited significantly greater spasticity in tail muscles compared with controls $(p<0.001$; Fig. $10 B)$.

\section{Discussion}

This study demonstrates that combined targeting of multiple mechanisms ordinarily limiting axonal regeneration can promote motor axonal regeneration, even in the extraordinarily challenging model of complete spinal cord transection. Spinal cord injury studies frequently avoid complete spinal cord transection: while it is the gold standard to provide evidence of axonal regeneration, it is extremely difficult to overcome the barriers of reactive glia, inhibitory extracellular matrix, and inhibitory adult white matter to achieve axonal regeneration beyond the lesion. In the present study, we find that combinations of cell bridges in the lesion site, growth factor gradients beyond the lesion, and stimulation of the intrinsic growth state of the neuron by cAMP injection support axonal regeneration into the lesion site and beyond. Importantly, we fail to see the same amount of regeneration unless each of these mechanisms that individually contributes to the failure of central axonal regeneration is targeted (Schwab and Bartholdi, 1996; Alto et al., 2009; Kadoya et al., 2009). Several lines of evidence support the observation that axons have regenerated in this study: (1) regenerating axons emerge from the midportions of the graft in the lesion site, where spared axons are unlikely to be located; (2) axons exhibit irregular trajectories, often with abrupt turns, rather than existing in tightly linear bundles typical of spared axons; (3) axons course through host gray matter that largely lacks the inhibitory molecules of adult CNS myelin; (4) axons are present only in regions of growth

\section{B Spasticity}

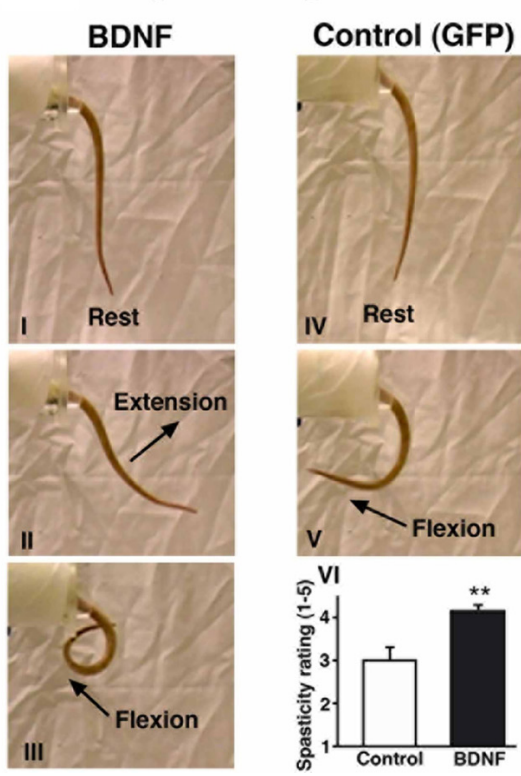

Figure 10. Functional outcomes after T3 complete transection and combinatorial therapy. Functional outcomes were measule

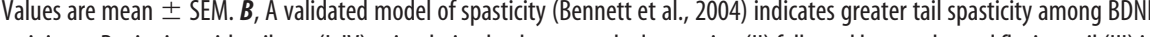
( Beginning with tail rest (I, IV), stimulation leads to a marked extension (II) followed by a prolonged flexion coil (III) in BDNF-treated rats, whereas only a moderate flexion is seen in control rats (V). AAV2-BDNF administration significantly increases

factor expression, a distribution that would not be predicted with axon sparing; and (5) serial sections demonstrate lesion completeness. The complete transection model, performed accurately, excludes the possibility that axonal sparing or neuroprotection results in improved anatomical or functional outcomes.

Yet despite motor axonal bridging beyond sites of spinal cord injury, functional outcomes in this study were worse after partial lesions, and spasticity worsened after complete transection. These "paradoxical" findings highlight the complexity of efforts to reconstruct injured adult neural circuitry. Regenerating motor axons in this study formed synapses, demonstrated both by highresolution confocal microscopy and ultrastructural analysis. Indeed, these regenerating axons formed synapses in target regions containing motor neurons and dendrites. Several mechanisms may account for worsened outcomes. First, BDNF induces synaptic plasticity both in the brain and after spinal cord injury (Figurov et al., 1996; Stoop and Poo, 1996; Jakeman et al., 1998; Boulenguez et al., 2010). In the spinal cord, these effects could generate spasticity and reflex hyperactivity. Transient growth factor expression for a time period sufficient to promote axonal growth, following by discontinuation of growth factor expression (Blesch and Tuszynski, 2007), could reduce spasticity. Second, adverse functional outcomes may have resulted from formation of contacts by regenerating axons with inappropriate target neurons or inappropriate regions of the dendritic/somal compartment. Regenerating axons followed the topography of growth factor expression, and improvement in functional outcomes might require restriction of regenerating axonal connectivity to specific subsets of cells or subregions of dendritic architecture (Tang et al., 2007). Retrograde targeting methods would be one 
means of achieving cell-specific neuronal growth factor expression (Fortun et al., 2009; Hollis et al., 2010), but the challenge of limiting growth factor expression to subregions of the dendritic tree would be substantially more difficult. Third, axonal regeneration may require interaction with specific rehabilitation strategies (García-Alías et al., 2009; Takeoka et al., 2011), approaches that will be tested in future studies.

Our findings that interventions promoting CNS plasticity can worsen functional outcomes are consistent with some previous studies. Takeoka et al. (2011) reported that grafts of olfactory ensheathing cells suppressed locomotor outcomes after spinal cord injury, because locomotion "paradoxically" improved when spinal cords were retransected several months after the original lesion/graft. A study by Basso et al. (1996) shed light on the existence of spontaneous plasticity that can occur in intrinsic spinal circuitry below lesions: rats underwent severe spinal cord contusions, followed 7 weeks later by complete transection; animals with these staged lesions demonstrated better functional outcomes than animals with initially complete transections. Numerous other studies confirm the existence of adaptive plasticity after spinal cord injury (Weidner et al., 2001; Bareyre et al., 2004; Courtine et al., 2008; Rosenzweig et al., 2010). Even complete transection is associated with a limited degree of adaptive plasticity and functional improvement due to reorganization of intrinsic circuits below the lesion (Basso et al., 1996), and these circuits can be further modified or "trained" by rehabilitation strategies (Harkema, 2001). Experimental interventions to enhance axonal plasticity can hypothetically interfere with adaptive plasticity, resulting in worsened outcomes.

In conclusion, we report axonal regeneration beyond the extraordinarily challenging model of complete spinal cord transection site using methods that simultaneously target multiple neural mechanisms responsible for regeneration failure. Yet, despite the presence of regenerating reticulospinal and raphespinal axons, functional measures worsen. These findings highlight the complexity of reconstructing the injured spinal cord, and the need to further control and shape axonal regeneration or increase the absolute number of regenerating axons. Most likely, improved functional outcomes resulting from axonal regeneration will require advances in each of these mechanisms.

\section{References}

Alilain WJ, Horn KP, Hu H, Dick TE, Silver J (2011) Functional regeneration of respiratory pathways after spinal cord injury. Nature 475:196-200.

Alto LT, Havton LA, Conner JM, Hollis ER 2nd, Blesch A, Tuszynski MH (2009) Chemotropic guidance facilitates axonal regeneration and synapse formation after spinal cord injury. Nat Neurosci 12:1106-1113.

Azizi SA, Stokes D, Augelli BJ, DiGirolamo C, Prockop DJ (1998) Engraftment and migration of human bone marrow stromal cells implanted in the brains of albino rats-similarities to astrocyte grafts. Proc Natl Acad Sci U S A 95:3908-3913.

Bareyre FM, Kerschensteiner M, Raineteau O, Mettenleiter TC, Weinmann O, Schwab ME (2004) The injured spinal cord spontaneously forms a new intraspinal circuit in adult rats. Nat Neurosci 7:269-277.

Basbaum AI, Zahs K, Lord B, Lakos S (1988) The fiber caliber of 5-HT immunoreactive axons in the dorsolateral funiculus of the spinal cord of the rat and cat. Somatosens Res 5:177-185.

Basso DM, Beattie MS, Bresnahan JC (1996) Graded histological and locomotor outcomes after spinal cord contusion using the NYU weight-drop device versus transection. Exp Neurol 139:244-256.

Bennett DJ, Sanelli L, Cooke CL, Harvey PJ, Gorassini MA (2004) Spastic long-lasting reflexes in the awake rat after sacral spinal cord injury. J Neurophysiol 91:2247-2258.

Blesch A, Tuszynski MH (2007) Transient growth factor delivery sustains regenerated axons after spinal cord injury. J Neurosci 27:10535-10545.

Bonner JF, Connors TM, Silverman WF, Kowalski DP, Lemay MA, Fischer I
(2011) Grafted neural progenitors integrate and restore synaptic connectivity across the injured spinal cord. J Neurosci 31:4675-4686.

Boulenguez P, Liabeuf S, Bos R, Bras H, Jean-Xavier C, Brocard C, Stil A, Darbon P, Cattaert D, Delpire E, Marsala M, Vinay L (2010) Downregulation of the potassium-chloride cotransporter KCC2 contributes to spasticity after spinal cord injury. Nat Med 16:302-307.

Buchli AD, Schwab ME (2005) Inhibition of Nogo: a key strategy to increase regeneration, plasticity and functional recovery of the lesioned central nervous system. Ann Med 37:556-567.

Cheng H, Cao Y, Olson L (1996) Spinal cord repair in adult paraplegic rats: partial restoration of hind limb function. Science 273:510-513.

Courtine G, Song B, Roy RR, Zhong H, Herrmann JE, Ao Y, Qi J, Edgerton VR, Sofroniew MV (2008) Recovery of supraspinal control of stepping via indirect propriospinal relay connections after spinal cord injury. Nat Med 14:69-74.

Fawcett JW (2006) Overcoming inhibition in the damaged spinal cord. J Neurotrauma 23:371-383.

Fawcett JW, Curt A, Steeves JD, Coleman WP, Tuszynski MH, Lammertse D, Bartlett PF, Blight AR, Dietz V, Ditunno J, Dobkin BH, Havton LA, Ellaway PH, Fehlings MG, Privat A, Grossman R, Guest JD, Kleitman N, Nakamura M, Gaviria M, et al. (2007) Guidelines for the conduct of clinical trials for spinal cord injury as developed by the ICCP panel: spontaneous recovery after spinal cord injury and statistical power needed for therapeutic clinical trials. Spinal Cord 45:190-205.

Figurov A, Pozzo-Miller LD, Olafsson P, Wang T, Lu B (1996) Regulation of synaptic responses to high-frequency stimulation and LTP by neurotrophins in the hippocampus. Nature 381:706-709.

Filbin MT (2006) Recapitulate development to promote axonal regeneration: good or bad approach? Philos Trans R Soc Lond B Biol Sci 361:1565-1574.

Fitch MT, Silver J (2008) CNS injury, glial scars, and inflammation: inhibitory extracellular matrices and regeneration failure. Exp Neurol 209:294-301.

Fortun J, Puzis R, Pearse DD, Gage FH, Bunge MB (2009) Muscle injection of AAV-NT3 promotes anatomical reorganization of CST axons and improves behavioral outcome following SCI. J Neurotrauma 26:941-953.

García-Alías G, Barkhuysen S, Buckle M, Fawcett JW (2009) Chondroitinase $A B C$ treatment opens a window of opportunity for task-specific rehabilitation. Nat Neurosci 12:1145-1151.

Gensel JC, Tovar CA, Hamers FP, Deibert RJ, Beattie MS, Bresnahan JC (2006) Behavioral and histological characterization of unilateral cervical spinal cord contusion injury in rats. J Neurotrauma 23:36-54.

Harkema SJ (2001) Neural plasticity after human spinal cord injury: application of locomotor training to the rehabilitation of walking. Neuroscientist 7:455-468.

He Z, Koprivica V (2004) The Nogo signaling pathway for regeneration block. Annu Rev Neurosci 27:341-368.

Hollis ER 2nd, Jamshidi P, Lorenzana AO, Lee JK, Gray SJ, Samulski RJ, Zheng B, Tuszynski MH (2010) Transient demyelination increases the efficiency of retrograde AAV transduction. Mol Ther 18:1496-1500.

Houle JD, Tom VJ, Mayes D, Wagoner G, Phillips N, Silver J (2006) Combining an autologous peripheral nervous system "bridge" and matrix modification by chondroitinase allows robust, functional regeneration beyond a hemisection lesion of the adult rat spinal cord. J Neurosci 26:7405-7415.

Hubli M, Bolliger M, Dietz V (2011) Neuronal dysfunction in chronic spinal cord injury. Spinal Cord 49:582-587.

Jakeman LB, Wei P, Guan Z, Stokes BT (1998) Brain-derived neurotrophic factor stimulates hindlimb stepping and sprouting of cholinergic fibers after spinal cord injury. Exp Neurol 154:170-184.

Jin Y, Tessler A, Fischer I, Houle JD (2000) Fibroblasts genetically modified to produce BDNF support regrowth of chronically injured serotonergic axons. Neurorehabil Neural Repair 14:311-317.

Jin Y, Fischer I, Tessler A, Houle JD (2002) Transplants of fibroblasts genetically modified to express BDNF promote axonal regeneration from supraspinal neurons following chronic spinal cord injury. Exp Neurol 177:265-275.

Jones LL, Sajed D, Tuszynski MH (2003) Axonal regeneration through regions of CSPG deposition after spinal cord injury: a balance of permissiveness and inhibition. J Neurosci 23:9276-9288.

Kadoya K, Tsukada S, Lu P, Coppola G, Geschwind D, Filbin MT, Blesch A, Tuszynski MH (2009) Combined intrinsic and extrinsic neuronal 
mechanisms facilitate bridging axonal regeneration one year after spinal cord injury. Neuron 64:165-172.

Knott GW, Holtmaat A, Trachtenberg JT, Svoboda K, Welker E (2009) A protocol for preparing GFP-labeled neurons previously imaged in vivo and in slice preparations for light and electron microscopic analysis. Nat Protoc 4:1145-1156.

Levi AD, Dancausse H, Li X, Duncan S, Horkey L, Oliviera M (2002) Peripheral nerve grafts promoting central nervous system regeneration after spinal cord injury in the primate. J Neurosurg 96:197-205.

Liu K, Lu Y, Lee JK, Samara R, Willenberg R, Sears-Kraxberger I, Tedeschi A, Park KK, Jin D, Cai B, Xu B, Connolly L, Steward O, Zheng B, He Z (2010) PTEN deletion enhances the regenerative ability of adult corticospinal neurons. Nat Neurosci 13:1075-1081.

Loy DN, Magnuson DS, Zhang YP, Onifer SM, Mills MD, Cao QL, Darnall JB, Fajardo LC, Burke DA, Whittemore SR (2002) Functional redundancy of ventral spinal locomotor pathways. J Neurosci 22:315-323.

Lu P, Jones LL, Snyder EY, Tuszynski MH (2003) Neural stem cells constitutively secrete neurotrophic factors and promote extensive host axonal growth after spinal cord injury. Exp Neurol 181:115-129.

Lu P, Yang H, Jones LL, Filbin MT, Tuszynski MH (2004) Combinatorial therapy with neurotrophins and cAMP promotes axonal regeneration beyond sites of spinal cord injury. J Neurosci 24:6402-6409.

Lu P, Jones LL, Tuszynski MH (2005) BDNF-expressing marrow stromal cells support extensive axonal growth at sites of spinal cord injury. Exp Neurol 191:344-360.

Murray KC, Nakae A, Stephens MJ, Rank M, D’Amico J, Harvey PJ, Li X, Harris RL, Ballou EW, Anelli R, Heckman CJ, Mashimo T, Vavrek R, Sanelli L, Gorassini MA, Bennett DJ, Fouad K (2010) Recovery of motoneuron and locomotor function after spinal cord injury depends on constitutive activity in 5-HT2C receptors. Nat Med 16:694-700.

Neumann S, Bradke F, Tessier-Lavigne M, Basbaum AI (2002) Regeneration of sensory axons within the injured spinal cord induced by intraganglionic cAMP elevation. Neuron 34:885-893.

Pearse DD, Pereira FC, Marcillo AE, Bates ML, Berrocal YA, Filbin MT, Bunge MB (2004) cAMP and Schwann cells promote axonal growth and functional recovery after spinal cord injury. Nat Med 10:610-616.

Peel AL, Zolotukhin S, Schrimsher GW, Muzyczka N, Reier PJ (1997) Efficient transduction of green fluorescent protein in spinal cord neurons using adeno-associated virus vectors containing cell type-specific promoters. Gene Ther 4:16-24.

Qiu J, Cai D, Dai H, McAtee M, Hoffman PN, Bregman BS, Filbin MT (2002) Spinal axon regeneration induced by elevation of cyclic AMP. Neuron 34:895-903.

Ramón-Cueto A, Cordero MI, Santos-Benito FF, Avila J (2000) Functional recovery of paraplegic rats and motor axon regeneration in their spinal cords by olfactory ensheathing glia. Neuron 25:425-435.

Rosenzweig ES, Courtine G, Jindrich DL, Brock JH, Ferguson AR, Strand SC, Nout YS, Roy RR, Miller DM, Beattie MS, Havton LA, Bresnahan JC, Edgerton VR, Tuszynski MH (2010) Extensive spontaneous plasticity of corticospinal projections after primate spinal cord injury. Nat Neurosci 13:1505-1510.

Sandrow HR, Shumsky JS, Amin A, Houle JD (2008) Aspiration of a cervical spinal contusion injury in preparation for delayed peripheral nerve grafting does not impair forelimb behavior or axon regeneration. Exp Neurol 210:489-500.

Schwab ME, Bartholdi D (1996) Degeneration and regeneration of axons in the lesioned spinal cord. Physiol Rev 76:319-370.

Sillar KT, Woolston AM, Wedderburn JF (1995) Involvement of brainstem serotonergic interneurons in the development of a vertebrate spinal locomotor circuit. Proc Biol Sci 259:65-70.

Steward O, Sharp K, Selvan G, Hadden A, Hofstadter M, Au E, Roskams J (2006) A re-assessment of the consequences of delayed transplantation of olfactory lamina propria following complete spinal cord transection in rats. Exp Neurol 198:483-499.

Stoop R, Poo MM (1996) Synaptic modulation by neurotrophic factors. Prog Brain Res 109:359-364.

Sun F, Park KK, Belin S, Wang D, Lu T, Chen G, Zhang K, Yeung C, Feng G, Yankner BA, He Z (2011) Sustained axon regeneration induced by codeletion of PTEN and SOCS3. Nature 480:372-375.

Takeoka A, Jindrich DL, Muñoz-Quiles C, Zhong H, van den Brand R, Pham DL, Ziegler MD, Ramón-Cueto A, Roy RR, Edgerton VR, Phelps PE (2011) Axon regeneration can facilitate or suppress hindlimb function after olfactory ensheathing glia transplantation. J Neurosci 31: $4298-4310$

Tang XQ, Heron P, Mashburn C, Smith GM (2007) Targeting sensory axon regeneration in adult spinal cord. J Neurosci 27:6068-6078

Taylor L, Jones L, Tuszynski MH, Blesch A (2006) Neurotrophin-3 gradients established by lentiviral gene delivery promote short-distance axonal bridging beyond cellular grafts in the injured spinal cord. J Neurosci 26:9713-9721.

Weidner N, Ner A, Salimi N, Tuszynski MH (2001) Spontaneous corticospinal axonal plasticity and functional recovery after adult central nervous system injury. Proc Natl Acad Sci U S A 98:3513-3518.

Xu XM, Guénard V, Kleitman N, Aebischer P, Bunge MB (1995) A combination of BDNF and NT-3 promotes supraspinal axonal regeneration into Schwann cell grafts in adult rat thoracic spinal cord. Exp Neurol 134:261272. 